\title{
Subsolidus Phase Relationships in the $\mathrm{ZnO}-\mathrm{In}_{2} \mathrm{O}_{3}-\mathrm{SnO}_{2}$ System
}

\author{
Steven P. Harvey, ${ }^{\star \ddagger}$ Kenneth R. Poeppelmeier, ${ }^{\S}$ and Thomas O. Mason ${ }^{\star, \dagger, \ddagger}$ \\ ${ }^{\ddagger}$ Department of Materials Science and Engineering, Materials Research Science and Engineering Center, Northwestern \\ University, Evanston, Illinois 60208 \\ ${ }^{\S}$ Department of Chemistry, Materials Research Science and Engineering Center, Northwestern University, Evanston,
} Illinois 60208

\begin{abstract}
The subsolidus phase relationships in the $\mathrm{ZnO}-\mathrm{InO}_{1.5}-\mathrm{SnO}_{2}$ system were investigated at $1275^{\circ} \mathrm{C}$ using $\mathrm{X}$-ray diffraction. Each of the end members of the ternary diagram is a transparent conducting oxide. There are two substantial solid solutions in the ternary phase space, the bixbyite solid solution $\mathrm{In}_{2-2 x} \mathrm{Zn}_{x} \mathrm{Sn}_{x} \mathrm{O}_{3}(x=0-0.40)$, and the indium substituted zinc stannate spinel, $\mathrm{Zn}_{(2-x)} \operatorname{Sn}_{(1-x)} \operatorname{In}_{2 x} \mathrm{O}_{4}(x=0-0.45)$. The bixbyite solid solution is an outstanding TCO, whereas the spinel is only moderately conducting. Along the $\mathrm{ZnO}-\mathrm{InO}_{1.5}$ binary, there is a series of transparent conducting homologous compounds $(\mathrm{ZnO})_{k} \cdot \operatorname{In}_{2} \mathrm{O}_{3}$ (where $\left.k=3,4,5,6,7,9,11\right)$. Within ternary phase space, these homologous compounds were found to exhibit negligible $\mathrm{Sn}$ solubility, and were always found to be compatible with the spinel. Equilibrium was difficult to achieve in the phase space between the homologous series compounds and the spinel, owing to sluggish kinetics. A procedure involving mixtures of prereacted spinel and the $\mathrm{Zn}_{11} \operatorname{In}_{2} \mathrm{O}_{14}(k=11)$ compound was developed, which allowed for more rapid approach to thermodynamic equilibrium, thereby allowing for the establishment of phase relationships near the $\mathrm{ZnO}$ corner of the phase diagram.
\end{abstract}

\section{Introduction}

$\mathrm{T}$ HIS study reports on the subsolidus phase relationships in the $\mathrm{ZnO}-\mathrm{In}_{2} \mathrm{O}_{3}-\mathrm{SnO}_{2}$ system at $1275^{\circ} \mathrm{C}$, hereafter referred to as the "ZITO" system. Compositions in this ternary phase space are of special interest owing to their high optical transparency combined with high electrical conductivity. As such, they found applications as transparent conducting oxides (TCOs). Each unary, binary, and ternary compound/solid solution in the $\mathrm{ZnO}-\mathrm{In}_{2} \mathrm{O}_{3}-\mathrm{SnO}_{2}$ phase diagram is reported to be a TCO if appropriately doped. ${ }^{1}$ More recently, compositions in the ZITO phase space have been investigated for transparent oxide semiconductor (TOS) applications, including amorphous ZITO thin films for transparent field-effect transistors. ${ }^{2-4}$

Of the end-members, tin-doped $\operatorname{In}_{2} \mathrm{O}_{3}$, known as indium-tin oxide or ITO, is the most well known and widely used TCO (e.g., as transparent electrodes for flat-panel displays), exhibiting room temperature conductivities as high as $13500 \mathrm{~S} / \mathrm{cm}^{5} \mathrm{Zinc}$ oxide can be rendered an n-type TCO by In or Sn doping, however, better donor-dopants exist (e.g., Al; Ga), with conductiv-

L. Levinson-contributing editor

\footnotetext{
Manuscript No. 24516. Received March 31, 2008; approved April 8, 2008.

This work was financially supported by the NSF Materials World Network program under grant no. DMR-0602521 (S. P. H., T. O. M.) and the NSF MRSEC program at Northwestern University under grant no. DMR-0520513 (T. O. M., K. R. P). This work made use of the J.B. Cohen X-ray Diffraction Facility supported by the Northwestern University MRSEC program.

${ }^{*}$ Member, The American Ceramic Society.

Author to whom correspondence should be addressed. e-mail: t-mason@northwestern.
} edu ities as high as $12000 \mathrm{~S} / \mathrm{cm} .{ }^{6,7}$ No appropriate donor-dopant for $\mathrm{SnO}_{2}$ exists in the $\mathrm{ZnO}-\mathrm{In}_{2} \mathrm{O}_{3}-\mathrm{SnO}_{2}$ system, but $\mathrm{SnO}_{2}$ is the most used TCO (by sheer volume, as a low emissivity coating on architectural glass), exhibiting conductivities as high as 9000 $\mathrm{S} / \mathrm{cm}$ (when doped by F). ${ }^{8}$ There is one binary compound in the $\mathrm{ZnO}-\mathrm{SnO}_{2}$ system, namely the $\mathrm{ZnSn}_{2} \mathrm{O}_{4}$ spinel, ${ }^{9}$ and at least seven "homologous series" compounds in the $\mathrm{ZnO}-\mathrm{In}_{2} \mathrm{O}_{3}$ system at the temperature of interest $\left(1275^{\circ} \mathrm{C}\right)$, whose formula is $(\mathrm{ZnO})_{k} \cdot \mathrm{In}_{2} \mathrm{O}_{3}(k=3,4,5,6,7,9,11) .{ }^{10}$ The zinc stannate spinel can be rendered moderately conductive by $\operatorname{In}_{2} \mathrm{O}_{3}$ doping. On the other hand, most of the homologous series compounds are outstanding TCOs, especially for lower values of $k .^{11-13}$

Although there are no true ternary compounds within the ZITO phase space, the authors demonstrated previously the existence of two extended solid solutions. The first involves zincand tin-cosubstitution of the unary bixbyite phase, $\mathrm{In}_{2-2 x} \mathrm{Zn}_{x} \mathrm{Sn}_{x} \mathrm{O}_{3}$, which exists over a wide range of compositions, i.e., $0 \leq x \leq 0.40 .{ }^{14}$ This extended range of cosolubility was rationalized on the basis of the nearly size-matched and isovalent nature of the substitution, i.e., two trivalent In species $\left(\mathrm{In}^{3+}\right)$ are being substituted by one divalent $\left(\mathrm{Zn}^{2+}\right)$ and one tetravalent species $\left(\mathrm{Sn}^{4+}\right)$. The bixbyite solid solution exhibits outstanding TCO properties over the complete range of compositions. ${ }^{14}$ The other solid solution involves $\mathrm{In}_{2} \mathrm{O}_{3}$ doping of the binary $\mathrm{ZnSn}_{2} \mathrm{O}_{4}$ spinel phase, whose formula is $\mathrm{Zn}_{(2-x)}$ $\mathrm{Sn}_{(1-x)} \mathrm{In}_{2 x} \mathrm{O}_{4}$. Similar to the bixbyite phase, this solid solution exists over a wide range of compositions, namely $0 \leq x \leq 0.45$. Again, this extended solubility was rationalized on the basis of size matching and isovalency. This is the reverse of the bixbyite cosubstitution; here, two species $\left(\mathrm{In}^{3+}\right)$ are being substituted for one divalent $\left(\mathrm{Zn}^{2+}\right)$ and one tetravalent species $\left(\mathrm{Sn}^{4+}\right) . \mathrm{In}_{2} \mathrm{O}_{3}$ doping of $\mathrm{ZnSn}_{2} \mathrm{O}_{4}$ spinel imparts respectable TCO character to an otherwise poorly conductive phase. ${ }^{9}$

The authors reported previously a partial phase diagram for the $\mathrm{ZnO}-\mathrm{In}_{2} \mathrm{O}_{3}-\mathrm{SnO}_{2}$ system at $1250^{\circ} \mathrm{C},{ }^{15}$ showing the existence of the two extended solid solutions and preliminary phase relations between them and the end-members. However, certain of the proposed compatibilities were in error, and a large portion of the phase diagram in the vicinity of the homologous series of compounds in the $\mathrm{ZnO}-\mathrm{In}_{2} \mathrm{O}_{3}$ binary was "under construction." Given the importance of the various ZITO TCO phases, the present work was undertaken to complete the subsolidus phase diagram for the $\mathrm{ZnO}-\mathrm{In}_{2} \mathrm{O}_{3}-\mathrm{SnO}_{2}$ system.

\section{Experimental Procedure}

Specimens were prepared by first drying the constituent oxides, $\mathrm{ZnO}, \mathrm{SnO}_{2}$, and $\mathrm{In}_{2} \mathrm{O}_{3}(99.99 \%$ or greater purity, Sigma-Aldrich, St. Louis, MO, or Alfa Aesar Inc., Ward Hill, MA), at $200^{\circ} \mathrm{C}$ overnight, followed by storage in a dessicator. Henceforth, $\mathrm{In}_{2} \mathrm{O}_{3}$ will be written as $\mathrm{InO}_{1.5}$, so that the resulting phase diagram will be on a cation ratio ( $\mathrm{Zn}$ :In:Sn) basis. From these dried starting materials, specimens were prepared by a thorough mixing of the constituent oxides in an agate mortar and pestle 
under acetone. Once dried, the powders were cold pressed into pellets $1-2 \mathrm{~mm}$ thick and $6.4 \mathrm{~mm}$ in diameter at $150 \mathrm{MPa}$.

In order to limit the tendency for $\mathrm{ZnO}$ evaporation at the sintering temperatures used, a multiple alumina crucible design was used. Pellets were stacked on the top of each other and loaded into a crucible slightly larger than its diameter, and covered with a packed bed of sacrificial powder of identical composition. A lid was placed over this crucible, which was placed under an upside down crucible of medium size, which was placed within a third crucible with a lid. The entire assembly was then placed inside a fourth crucible with a lid. Specimens were then fired at $1275^{\circ} \mathrm{C}$ for $24-72 \mathrm{~h}$, followed by air quenching to room temperature. The specimens were ground and repressed into pellets for the second firing, which was heated again for 24-72 $\mathrm{h}$ at $1275^{\circ} \mathrm{C}$, followed by air quenching to room temperature. All specimens were subjected to at least one regrinding/ sintering step. The weight of a given specimen (pellet and powder bed) was measured carefully before and after the two-step firing process. Overall weight loss was $<1 \%$ in all cases. The weight loss of the embedded pellets should be significantly smaller.

Phase evolution was monitored by X-ray diffraction (XRD) on a Rigaku diffractometer (Rigaku Inc., Tokyo, Japan) using a nonmonochromated $\mathrm{Cu} K_{\alpha}$ source with a beryllium $K_{\beta}$ filter and a scintillation detector. The minimum phase fraction that can be detected with this system is $\sim 1 \%$. The minimum lattice parameter changes that can be detected are conservatively estimated at $\pm 0.001 \mathrm{~A}$; this resolution was more than adequate for the lattice parameter determinations in the present work. Powder patterns were collected from $5^{\circ}$ to $70^{\circ} 2 \theta$; typical scans utilized a step of $0.05^{\circ} 2 \theta$ with a count time of $3 \mathrm{~s}$. Count times as long as $8 \mathrm{~s}$ were sometimes used for those compositions where small amounts of certain phases were present. Accurate lattice parameters were obtained by mixing specimen powder with $40 \mathrm{wt} \%$ of crystalline silicon powder (99.9985\% purity, Alfa Aesar Inc.) to correct for peak displacement errors. The Alfa Aesar silicon used as a standard was compared with the NIST 640c silicon standard material; within experimental uncertainty, the lattice parameters of the NIST 640c material were identical to the Alfa Aesar crystalline silicon material. For all specimens the Jade 8 software package (Materials Data Inc., Livermore, CA) was utilized for phase analysis.

\section{Results and Discussion}

The $1275^{\circ} \mathrm{C} \mathrm{ZnO}-\mathrm{InO}_{1.5}-\mathrm{SnO}_{2}$ subsolidus phase diagram is shown in Fig. 1, along with the specimens used to identify the phase relationships, except for those in the zinc-rich corner of the diagram, which are discussed in detail later. Figure 1 is the result of over 80 compositions/specimens, the data for which are summarized in Table A1. In Fig. 1, single-phase specimens are indicated by squares, two-phase specimens are indicated by diamonds, and three-phase specimens are indicated by triangles.

A detailed discussion of the phase relationships, starting with the bounding binary systems, will be presented. However, before discussing in more detail the phase relationships in this system, a few preliminary observations should be made:

(1) No new compounds or structures were discovered during the course of this study.

(2) The two vertical lines in Fig. 1, i.e., the cosubstitution (bixbyite, spinel) phases, were confirmed in terms of their extent and terminal solubilities. ${ }^{14,15}$

(3) The bixbyite and spinel solid solutions are each compatible with tin oxide, as reported previously. ${ }^{15}$

\section{(1) The Unary (End-Member) Phases}

The end-member oxides in this ternary system each crystallize in a different structure. Indium oxide crystallizes in the cubic $c$-type rare earth sesquioxide structure (Ia3) and is often described as a distorted fluorite structure, with one-quarter of the anion sites vacant. ${ }^{16}$ Tin oxide crystallizes in a tetragonal structure

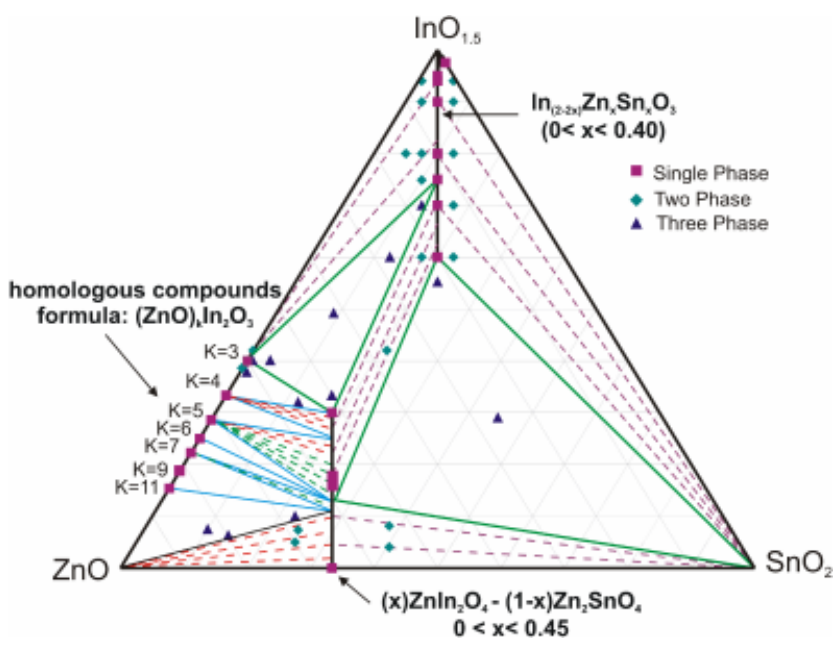

Fig. 1. Subsolidus phase diagram of the $\mathrm{ZnO}-\mathrm{InO}_{1.5}-\mathrm{SnO}_{2}$ system at $1275^{\circ} \mathrm{C}$, where solid lines are tie triangles, and dotted lines are tie lines showing areas of two-phase equilibrium. The two heavy lines representing a solid solution are separately labeled. The various dots show the compositions synthesized in this study (except between the $k 4$ and $k 11$ tie lines, which are shown in Fig. 3). Single-phase specimens are shown as a square, two-phase specimens are shown as a diamond, and three-phase specimens are shown as a triangle.

$\left(\mathrm{P}_{2} /\right.$ mnm $)$, which is isostructural with rutile, ${ }^{17}$ while zinc oxide is hexagonal, crystallizing in the wurtzite structure $\left(P 6_{3} m c\right) .{ }^{18}$

Of the end members, $\mathrm{ZnO}$ and $\mathrm{SnO}_{2}$ are represented as point compounds in the diagram of Fig. 1. The evidence substantiating negligible solid solubility in these phases, as well as for the negligible solid solubility of $\mathrm{ZnO}$ in $\mathrm{In}_{2} \mathrm{O}_{3}$, will be presented under the relevant binary phase equilibria (below). In contrast, the well-known solid solubility of $\mathrm{SnO}_{2}$ in $\mathrm{In}_{2} \mathrm{O}_{3}$ (ITO), as represented in Fig. 1, will be described under the $\mathrm{InO}_{1.5}-\mathrm{SnO}_{2}$ binary discussion to follow.

\section{(2) The Bounding Binary Systems}

(A) InO ${ }_{1.5}-\mathrm{SnO}_{2}$ System: In the $\mathrm{InO}_{1.5}-\mathrm{SnO}_{2}$ binary, the substitution of tin for indium in the bixbyite phase leads to the most well-known TCO, $\operatorname{In}_{(2-2 x)} \mathrm{Sn}_{2 x} \mathrm{O}_{3}$ or ITO. Gonzalez-Aviles conducted the most definitive study of Sn solubility in $\mathrm{In}_{2} \mathrm{O}_{3}$ by annealing nano-powders having excess $\mathrm{Sn}$ content at various temperatures. ${ }^{19}$ The approach to equilibrium was followed by in situ electrical measurements (conductivity, Seebeck coefficient) and ex situ XRD as the excess $\mathrm{SnO}_{2}$ precipitated from the bixbyite major phase as second-phase rutile particles. Based upon established bixbyite lattice parameter-composition relations, the solubility of $\mathrm{Sn}$ in bixbyite was confirmed to be 1.4 cation percent at $1100^{\circ} \mathrm{C}$ and 2.9 cation percent at $1350^{\circ} \mathrm{C}$. This would put the solubility at approximately 2.0 cation percent at $1275^{\circ} \mathrm{C}$, in good agreement with the phase boundary reported by Heward and Swenson. ${ }^{20}$ This solubility level is reflected in the diagram of Fig. 1. It should be stressed that much higher Sndoping levels can be achieved under metastable synthesis levels, e.g., in thin films and nanocrystalline powders. For example, in another study by Gonzalez et al., ${ }^{21}$ a tin content of 8.6 cation percent was determined for a commercial nanocrystalline ITO.

In contrast, the solubility of indium in $\mathrm{SnO}_{2}$ appears to be negligibly small. In the present work, within experimental uncertainty $( \pm 0.001 \AA)$, no significant difference was observed in the $\mathrm{SnO}_{2}$ lattice parameter in ternary assemblages versus that of pure $\mathrm{SnO}_{2}$. This is consistent with the results of Heward and Swenson, ${ }^{20}$ Bates et al., ${ }^{22}$ and Edwards and Mason, ${ }^{23}$ but differs from the diagram of Enoki et al. ${ }^{24} \mathrm{We}$ have therefore indicated $\mathrm{SnO}_{2}$ as a point compound in the diagram of Fig. 1.

At high temperatures an additional $\mathrm{In}_{4} \mathrm{Sn}_{3} \mathrm{O}_{12}$ phase has been reported in the $\mathrm{In}_{2} \mathrm{O}_{3}-\mathrm{SnO}_{2}$ binary, however, it has only been 
reported at temperatures above $1300^{\circ} \mathrm{C} .^{21}$ This phase was never observed in the present study at $1275^{\circ} \mathrm{C}$.

(B) $\mathrm{ZnO}-\mathrm{SnO}_{2}$ System: There is no reported phase diagram for the $\mathrm{ZnO}-\mathrm{SnO}_{2}$ system. ${ }^{25}$ Two phases have been reported in the binary - an ilmenite $\left(\mathrm{ZnSnO}_{3}\right)$ and a spinel $\left(\mathrm{Zn}_{2} \mathrm{SnO}_{4}\right)$. The ilmenite phase is reported to be stable only at low temperatures $\left(<600^{\circ} \mathrm{C}\right)$ and has only been prepared by an ion exchange method. ${ }^{26}$ At elevated temperatures, the system is known to contain the intermediate spinel compound $\mathrm{Zn}_{2} \mathrm{SnO}_{4}$, with two-phase regions between the end members and the spinel. This was reported by Palmer and Poeppelmeier, ${ }^{27}$ and was confirmed in the present study. There is no evidence of significant solid solubility of either tin or zinc in the spinel, as evidenced by negligible lattice parameter changes (within experimental uncertainty of $\pm 0.001 \AA$ ) of the spinel in ternary assemblages vis-àvis undoped $\mathrm{ZnSn}_{2} \mathrm{O}_{4}{ }^{27}$

The most definitive work on $\mathrm{Sn}$ doping in $\mathrm{ZnO}$ was that of Peiteado et al. ${ }^{28}$ using a solution-based synthesis method, who found that $<0.1 \mathrm{~mol} \%$ of $\mathrm{SnO}_{2}$ is soluble in $\mathrm{ZnO}$. We similarly saw no change of lattice parameter between undoped $\mathrm{ZnO}$ and $\mathrm{ZnO}$ in ternary assemblages (within experimental uncertainty of $\pm 0.001 \AA$ ). We have, therefore, displayed $\mathrm{ZnO}$ as a point compound along this join.

We have similarly displayed $\mathrm{SnO}_{2}$ as a point compound along the $\mathrm{ZnO}-\mathrm{SnO}_{2}$ join because within experimental error $( \pm 0.001$ $\AA)$, there was no observable change in lattice parameter between the $\mathrm{SnO}_{2}$ in ternary assemblages versus that of undoped $\mathrm{SnO}_{2}$. To the authors' knowledge, there has been no definitive study of $\mathrm{ZnO}$ doping in $\mathrm{SnO}_{2}$.

(C) $\mathrm{ZnO}-\mathrm{InO}_{1.5}$ System: The $\mathrm{ZnO}-\mathrm{InO}_{1.5}$ system was extensively investigated by Moriga et al., ${ }^{10}$ who published the binary $\mathrm{ZnO}-\mathrm{InO}_{1.5}$ phase diagram from $1100^{\circ}$ to $1400^{\circ} \mathrm{C}$. This system consists of a series of homologous compounds of the formula $(\mathrm{ZnO})_{k} \cdot \mathrm{In}_{2} \mathrm{O}_{3}$ (where $k=3,4,5,6,7,9,11,13$ ). These materials are described as having $k$ number of $\mathrm{ZnO}$ layers, sandwiched between two $\mathrm{InO}_{1.5}$ layers. Homologous compounds with odd $k$ values are rhombohedral and crystallize in the $R \overline{3} m$ space group. Those with even $k$ values are tetragonal and crystallize in the $P 6_{3} / m m c$ space group. In either case the structure is characterized by a short $a$-axis $(3.2-3.4 \AA$ ) and a long $c$-axis (e.g., $42.5 \AA$ for $k=3$ ) for both the even and odd $k$ values. As the $k$ value increases, the $c$-axis of the unit cell increases while the $a$-axis decreases slightly. Moriga's work ${ }^{10}$ suggests that only $k$ values of $3,4,5,7,9$, and 11 should be present at $1275^{\circ} \mathrm{C}$, with an additional $k=6$ phase being stable at slightly higher temperatures $\left(\geq 1325^{\circ} \mathrm{C}\right.$ ). The present work detected all seven homologous series compounds in ternary phase space. Therefore, we have opted to show all seven compounds along the $\mathrm{ZnO}-\mathrm{InO}_{1.5}$ binary in Fig. 1 .

\section{(3) The Ternary $\mathrm{ZnO}-\mathrm{InO}_{1.5}-\mathrm{SnO}_{2}$ System}

Although there are no true ternary compounds in the $\mathrm{ZnO}$ $\mathrm{InO}_{1.5}-\mathrm{SnO}_{2}$ system of Fig. 1, there are two significant TCO solid solutions in the ternary phase space, one being tin- and zinc-codoped indium oxide, $\mathrm{In}_{(2-2 x)} \mathrm{Sn}_{x} \mathrm{Zn}_{x} \mathrm{O}_{3}$, or bixbyite solid solution. The second is the indium-substituted $\mathrm{Zn}_{2} \mathrm{SnO}_{4}$ spinel, $\mathrm{Zn}_{(2-x)} \mathrm{Sn}_{(1-x)} \mathrm{In}_{2 x} \mathrm{O}_{4}$. These appear as long vertical lines (having equal $\mathrm{Zn}$ :Sn ratio) in the diagram. Each solid solution will be discussed separately, followed by the multiphase regions. The discussion of the multiphase regions will progress from the indium-rich corner to the tin-rich corner, and finally to the zincrich corner, with its complicated phase relationships involving the $(\mathrm{ZnO})_{k} \cdot \mathrm{In}_{2} \mathrm{O}_{3}$ homologous compounds.

The ternary diagram in Fig. 1 differs slightly from the previously reported preliminary diagram at $1250^{\circ} \mathrm{C}$. ${ }^{15}$ One major discrepancy between the preliminary diagram and the present work is that there was no detectable solubility of tin or zinc into the $(\mathrm{ZnO})_{k} \cdot \mathrm{In}_{2} \mathrm{O}_{3}$ series of homologous compounds. In addition, the two-phase equilibrium observed in the current study between the bixybite and spinel solid solutions was not reported previously.
(A) The $\mathrm{In}_{(2-2 x)} \mathrm{Sn}_{x} \mathrm{Zn} n_{x} \mathrm{O}_{3}$ Bixbyite Solid Solution: The codoping of tin and zinc for indium significantly increases the amount of substitution in the bixbyite phase. As stated previously, via bulk synthesis approximately 2.0 cation percent of tin can substitute for indium in $\mathrm{In}_{2} \mathrm{O}_{3},{ }^{19}$ and the In solubility in $\mathrm{SnO}_{2}$ is negligible. ${ }^{20}$ Yet as codopants, up to $40 \%$ of the indium can be replaced with zinc and tin $\left(x=0.4\right.$ in $\left.\operatorname{In}_{(2-2 x)} \operatorname{Sn}_{x} \mathrm{Zn}_{x} \mathrm{O}_{3}\right)$, while still maintaining the bixbyite (Ia3) structure. This has been attributed to the nearly size-matched and isovalent nature of the cosubstitution. ${ }^{14,29}$

Even though as much as $40 \%$ of the indium in the bixbyite solid solution can be replaced with zinc and tin (a desirable situation, given the relative scarcity of indium) the solid solution is still an excellent TCO. For example, a recent study of thin films and the bixbyite solid solution reported a conductivity of 4000 $\mathrm{S} / \mathrm{cm}$ at an $x \sim 0.3$ composition in $\operatorname{In}_{(2-2 x)} \mathrm{Sn}_{x} \mathrm{Zn}_{x} \mathrm{O}_{3}$ in pulsed laser-deposited thin films. ${ }^{30}$ Early bulk work showed only a small change ( $\sim 50 \%$ increase) of conductivity versus codoping $(x)$ in the solid solution. ${ }^{30}$

One might initially expect a much larger change in the conductivity as a function of codoping level than what is seen in the bixbyite solid solution. The relatively small increase in conductivity across the solution range is actually a result of the carrier generation mechanism in the solid solution. The charge carriers arise from an inherent off-stoichiometry, i.e. the equilibrium composition for the bixbyite solid solution lies slightly to the tin excess side of nominal stoichiometry, such that tin donors outnumber zinc acceptors (i.e., $\left[\mathrm{Sn}_{\mathrm{In}}^{*}\right]>\left[\mathrm{Zn}_{\mathrm{In}}^{\prime}\right]$ and $n=\left[\mathrm{Sn}_{\mathrm{In}}^{*}\right]-$ $\left.\left[\mathrm{Zn}_{\text {In }}^{\prime}\right]>0\right)$. This concept is illustrated in the schematic of the bixbyite solid solution phase field within the $\mathrm{ZnO}-\mathrm{InO}_{1.5}-\mathrm{SnO}_{2}$ phase diagram, shown in Fig. 2. In addition, this production of charge carriers by an inherent off-stoichiometry is an explanation for the small variance in the conductivity across the solution range, in spite of $40 \%$ of the indium being exchanged for tin and zinc. Note that the trend in Fig. 2 is schematic only; precise offstoichiometries are small and difficult to quantify.

The lattice parameters of the bixbyite solid solution specimens continually decreased across the solution range, from $10.12 \AA$ for $\mathrm{In}_{2} \mathrm{O}_{3}$ to $9.99 \AA$ for $x=0.4$ in $\operatorname{In}_{(2-2 x)} \mathrm{Sn}_{x} \mathrm{Zn}_{x} \mathrm{O}_{3}$. The lattice parameters were thus used to obtain tie lines for various multiphase regions involving the bixbyite solid solution; given the $\pm 0.001 \AA$ experimental uncertainty, this leads to an uncertainty of $x= \pm 0.003$ in the reported phase field locations involving the bixbyite solid solution. There was no noticeable increase in the terminal cosolubility $(x=0.4)$ at $1275^{\circ} \mathrm{C}$ from that found by Palmer et al. ${ }^{14}$ at $1250^{\circ} \mathrm{C}$, within experimental uncertainty.

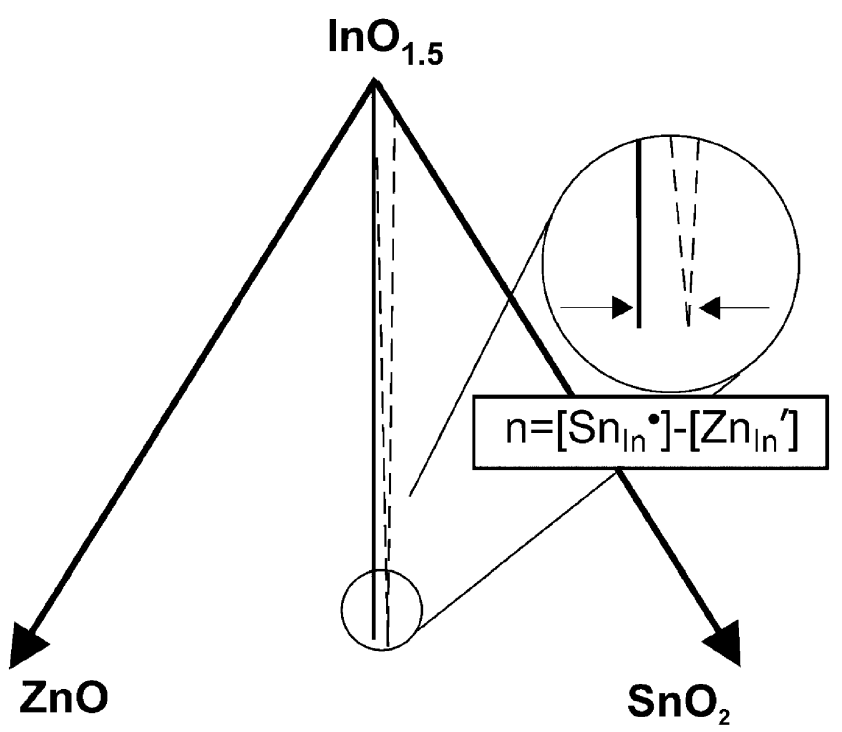

Fig. 2. Schematic of the bixbyite solid solution phase field within the $\mathrm{ZnO}-\mathrm{InO}_{1.5}-\mathrm{SnO}_{2}$ phase space. 
(B) The Spinel $\mathrm{Zn}_{(2-x)} \mathrm{Sn}_{(1-x)} \mathrm{In}_{2 x} \mathrm{O}_{4}$ Solid Solution: The spinel solid solution $\mathrm{Zn}_{(2-x)} \mathrm{Sn}_{(1-x)} \operatorname{In}_{2 x} \mathrm{O}_{4}(x=0-0.45)$ is indiumdoped $\mathrm{Zn}_{2} \mathrm{SnO}_{4}$, which is an inverse spinel with a face-centered cubic unit cell (space group $F d \overline{3} m$ ). In $\mathrm{Zn}_{2} \mathrm{SnO}_{4}$, the tin ions are in octahedral coordination, while the zinc ions are half in tetrahedral coordination, and half in octahedral coordination. ${ }^{31}$ The spinel solid solution exhibits an increase in lattice parameter with indium substitution, from $\sim 8.66 \AA$ for $\mathrm{Zn}_{2} \mathrm{SnO}_{4}$ (or $x=0$ ) to $\sim 8.77 \AA$ for $\mathrm{Zn}_{1.55} \mathrm{Sn}_{0.55} \mathrm{In}_{0.90} \mathrm{O}_{4}$ (or $x=0.45$ ). As with the bixbyite solid solution, the spinel lattice parameters were used to establish tie lines in various multiphase regions involving the spinel phase. The experimental uncertainty in determining lattice parameters leads to an uncertainty of $x= \pm 0.0033$ for the reported phase field locations involving the spinel solid solution.

The compositions along the solid solution range from insulating $\left(<10^{-6} \mathrm{~S} / \mathrm{cm}\right)$ and transparent (or white as powders, at $x=0)$ to moderately conductive $(\sim 3 \mathrm{~S} / \mathrm{cm})$ and light green (at $x=0.45) .{ }^{9}$ There was no noticeable increase in the terminal solubility of indium $(x=0.45)$ at $1275^{\circ} \mathrm{C}$ versus that found by Palmer et al. ${ }^{14}$ at $1250^{\circ} \mathrm{C}$, within experimental uncertainty.

(C) The Indium-Rich Region: As seen in Fig. 1, there are two-phase regions emanating from the $\mathrm{InO}_{1.5}$ end-member of the ternary diagram, while the bixbyite solid solution extends vertically away from $\mathrm{InO}_{1.5}$. On the $\mathrm{SnO}_{2}$ side of the bixbyite solid solution the entire range of solid-solution compositions is in equilibrium with essentially undoped $\mathrm{SnO}_{2}$, forming an extensive two-phase region. On the $\mathrm{ZnO}$ side of the bixbyite solid solution there are two distinct two-phase regions and one compatibility triangle involving the cosubsituted bixbyite phase.

Starting from the $\mathrm{InO}_{1.5}$ vertex, the first of these two phase regions has cosubstituted bixbyite in equilibrium with the layered $k=3$ homologous series compound $\mathrm{In}_{2} \mathrm{Zn}_{3} \mathrm{O}_{6}$ for bixbyite cosubstitutions up to $25 \%\left(x=0.25\right.$ in $\left.\operatorname{In}_{(2-2 x)} \mathrm{Sn}_{x} \mathrm{Zn}_{x} \mathrm{O}_{3}\right)$. A ternary compatibility triangle is then found between the $x=0.25$ bixbyite, the $k=3$ homologous series compound $\left(\operatorname{In}_{2} \mathrm{Zn}_{3} \mathrm{O}_{6}\right)$, and the end member of the In-substituted $\mathrm{Zn}_{2} \mathrm{SnO}_{4}$ spinel $\left(x=0.45\right.$ in $\mathrm{Zn}_{(2-x)} \mathrm{Sn}_{(1-x)} \mathrm{In}_{2 x} \mathrm{O}_{4}$ or $\left.\mathrm{Zn}_{1.55} \mathrm{Sn}_{0.55} \mathrm{In}_{0.90} \mathrm{O}_{4}\right)$. The bixbyite composition in this ternary compatibility was obtained by synthesis of a specimen within the triangle, and subsequent refinement of the lattice parameters of the bixbyite peaks, which vary continuously along the bixbyite solid solution line. Beyond the $x=0.25$ bixbyite composition, more heavily codoped bixbyite specimens $(x=0.25-0.40)$ are in equilibrium with the spinel solid solution at high indium contents $(x=0.20-0.45$ in $\left.\mathrm{Zn}_{(2-x)} \mathrm{Sn}_{(1-x)} \mathrm{In}_{2 x} \mathrm{O}_{4}\right)$.

(D) The Tin-Rich Region: There are several two-phase regions and one compatibility triangle involving the $\mathrm{SnO}_{2}$ end member of the ternary diagram, as shown in Fig. 1. The first of these two-phase regions has $\mathrm{SnO}_{2}$ in equilibrium with the full range of the bixbyite solid solution. The second two-phase region emanating from the $\mathrm{SnO}_{2}$ end member has $\mathrm{SnO}_{2}$ in equilibrium with $\mathrm{Zn}_{(2-x)} \mathrm{Sn}_{(1-x)} \mathrm{In}_{2 x} \mathrm{O}_{4}$ spinels of lower, but varying, indium contents $(x=0-0.20)$. The compatibility triangle involves $\mathrm{SnO}_{2}$ in equilibrium with the $\mathrm{Zn}_{1.8} \mathrm{Sn}_{0.80} \mathrm{In}_{0.4} \mathrm{O}_{4}$ spinel $\left(x=0.20\right.$ in $\left.\mathrm{Zn}_{(2-x)} \mathrm{Sn}_{(1-x)} \mathrm{In}_{2 x} \mathrm{O}_{4}\right)$ as well at the end member of the bixbyite solid solution $\left(\operatorname{In}_{1.2} \mathrm{Sn}_{0.40} \mathrm{Zn}_{0.40} \mathrm{O}_{3}\right)$. The determinations of spinel and bixbyite compositions in the compatibility triangle were based upon refinement of their lattice parameters in three-phase assemblages made within the triangle.

(E) The Zinc-Rich Region: Establishing equilibrium phase boundaries in the zinc-rich area of the ternary phase space proved difficult. As mentioned previously, along the $\mathrm{ZnO}$ $\mathrm{InO}_{1.5}$ binary there is a series of homologous compounds of the formula $(\mathrm{ZnO})_{k} \cdot \mathrm{In}_{2} \mathrm{O}_{3}$ (where $k=3,4,5,7,9,11$ ), present at $1275^{\circ} \mathrm{C}$. Unfortunately, the standard procedure for establishing phase equilibrium (mixing molar ratios of $\mathrm{ZnO}, \mathrm{InO}_{1.5}$, and $\mathrm{SnO}_{2}$ and subjecting them to multiple grindings and refirings) led to anomalous phase relationships.

In particular, the homologous compounds with higher indium content $(k=3,4,5)$, once formed, were very sluggish to react with other phases so as to achieve true equilibrium. Although the phase assemblages achieved by reacting the end- members $\left(\mathrm{ZnO}, \mathrm{In}_{2} \mathrm{O}_{3}, \mathrm{SnO}_{2}\right)$ consistently showed homologous series compounds in equilibrium with spinels of varying compositions, the tie lines obtained (based upon spinel lattice parameters) were counterintuitive, and the higher- $k$ homologous compounds were largely absent.

Various attempts were made to solve the problem. Mixtures of spinel (several different spinel compositions were used) and $\mathrm{ZnO}$ were employed, as well as starting with the $k=11$ homologous compound $\left(\mathrm{Zn}_{11} \mathrm{In}_{2} \mathrm{O}_{14}\right)$ as the zinc source, and adding to that $\mathrm{InO}_{1.5}$ and $\mathrm{SnO}_{2}$. Both approaches suffered the same problem (rapid formation of the low- $k$ homologous compounds, followed by sluggish kinetics) as encountered previously using simple mixtures of $\mathrm{ZnO}, \mathrm{InO}_{1.5}$, and $\mathrm{SnO}_{2}$.

A solution was ultimately found which used mixtures of prereacted $k=11 \mathrm{Zn}_{11} \mathrm{In}_{2} \mathrm{O}_{14}$ homologous compound and spinels of various compositions. In this case in order for equilibrium to be reached, the In-doped spinel $\mathrm{Zn}_{(2-x)} \mathrm{Sn}_{(1-x)} \mathrm{In}_{2 x} \mathrm{O}_{4}$ serves as the indium source for the decomposition of the $k=11$ homologous compound into homologous compounds with lower $k$ values, and the $\mathrm{Zn}_{11} \mathrm{In}_{2} \mathrm{O}_{14}$ compound serves as the zinc source for the formation of spinel with lower indium content than that of the spinel in the initial mixture.

This method proved successful in achieving equilibrium in this region of the diagram where all other attempts failed. It is believed that equilibrium was achieved for the following reasons:

1. Conflicting phase relationships were never present, as was frequently the case with other methods used, i.e., although homologous compounds were always detected in this region of the diagram, homologous compounds were never detected at zinc contents higher than the zinc content of the next homologous compound in the series.

2. For many different samples at high indium content (see the two-phase regions for $\mathrm{Zn}_{4} \mathrm{In}_{2} \mathrm{O}_{7}, \mathrm{Zn}_{5} \mathrm{In}_{2} \mathrm{O}_{8}$, and spinel) a secondary confirmation of equilibrium was possible. Refinement of the spinel lattice parameters to obtain the composition of the spinel was a perfect match to the tie line from the $k$-phase to the appropriate spinel composition, while passing through the overall composition point of the specimen on the phase diagram.

This zinc-rich region of the phase diagram is displayed in Fig. 3. Figure 3 also shows the various tie lines between $\mathrm{Zn}_{11} \mathrm{In}_{2} \mathrm{O}_{14}$ and the different spinel compositions utilized in

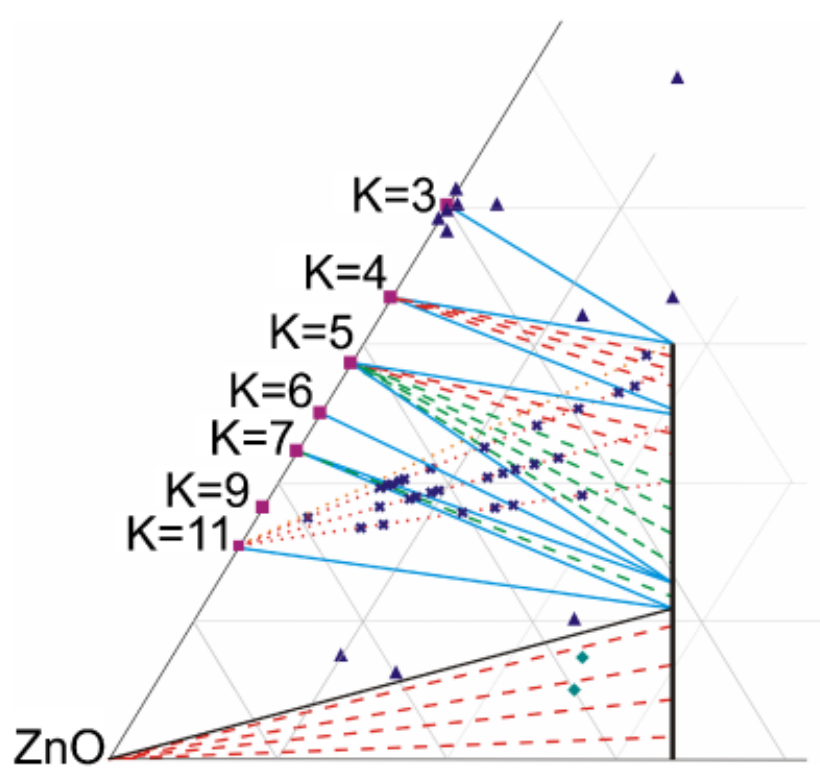

Fig. 3. Zinc-rich region of the $\mathrm{ZnO}-\mathrm{InO}_{1.5}-\mathrm{SnO}_{2}$ phase diagram at $1275^{\circ} \mathrm{C}$. The $k$ value correspond to the phase in the $(\mathrm{ZnO})_{k} \cdot \mathrm{In}_{2} \mathrm{O}_{3}$ series of compounds. The dashed lines are areas of two-phase equilibrium, while the dotted line between the $k=11$ compound and spinel of various compositions are the joins along which mixtures of $k 11$ and spinel were prepared. 
this method of synthesis, as well as all mixtures of the $\mathrm{Zn}_{11} \mathrm{In}_{2} \mathrm{O}_{14}$ compound and spinel that were used (marks on the tie lines). Because of the decrease in reaction activity for spinel compounds of lower indium content, equilibrium proved easiest to achieve for those samples created on tie lines with the highest indium content in the spinel. In such cases the refined lattice parameters of the spinel in the multiphase specimen matched perfectly with the tie line through the point of synthesis on the phase diagram back to the appropriate $k$-phase. However, for spinel compounds with $<20 \%$ indium, the indium content of the spinel predicted via the lattice parameter refinement of the spinel lagged behind that which was expected via the tie line.

One possible explanation of this apparent discrepancy in the indium content of the spinel to that of the expected tie line is that the homologous compounds are not point compounds in the ternary diagram. To probe this behavior, several different substitutions were attempted for the $k=3$ homologous compound $\left(\mathrm{Zn}_{3} \mathrm{In}_{2} \mathrm{O}_{6}\right)$. The substitution attempts included codoping of the indium site with tin and zinc (at both 3\% and 5\% levels), substitution of tin for zinc (both $1 \%$ and $3 \%$ levels), as well as indium substitution for zinc, and zinc substitution for indium (both at $1 \%$ levels). All these methods of doping the $k=3$ homologous compound proved unsuccessful. All specimens were clearly two-phase in nature (most having entered a three phase equilibrium region as seen in Fig. 3) and no changes in the lattice parameters of the $\mathrm{Zn}_{3} \mathrm{In}_{2} \mathrm{O}_{6}$ compound were ever detected.

Although this method was successful for proving $\mathrm{Zn}_{3} \mathrm{In}_{2} \mathrm{O}_{6}$ to be a point compound, it could not be used for the homologous compounds with $k>3$, owing to the kinetic issues discussed previously. To probe the dupability of the higher $k$ homologous compounds, lattice parameters (corrected through the use of silicon as a standard) were obtained for all the homologous compounds in various multiphase assemblages. No changes in the lattice parameters greater than two-tenths of $1 \%$ were observed; therefore, within this level of detection, there is no apparent $\mathrm{Sn}$ solubility in any of the homologous series compounds, as reflected in the phase diagrams (Figs. 1, 3 and 4).

Because the homologous series compounds appear to be point compounds, the disagreement between spinel compositions using XRD lattice parameter and the tie lines shown in Fig. 3 for starting spinels with $x<0.2$ in $\mathrm{Zn}_{(2-x)} \operatorname{Sn}_{(1-x)} \operatorname{In}_{2 x} \mathrm{O}_{4}$ is attributed to sluggish kinetics. Furthermore, for assemblages on reaction lines between $k=11 \mathrm{Zn}_{11} \mathrm{In}_{2} \mathrm{O}_{14}$ and spinels with $x<0.2$, the diffraction peaks of the $k=11$ phase swamped out those of the spinel, such that it became impossible to determine spinel lattice parameter.

In these cases, given the relative ease of determining which $k$ phase homologous compound(s) are stable in a given multiphase assemblage, we reverted to the detection of compatibility trian-

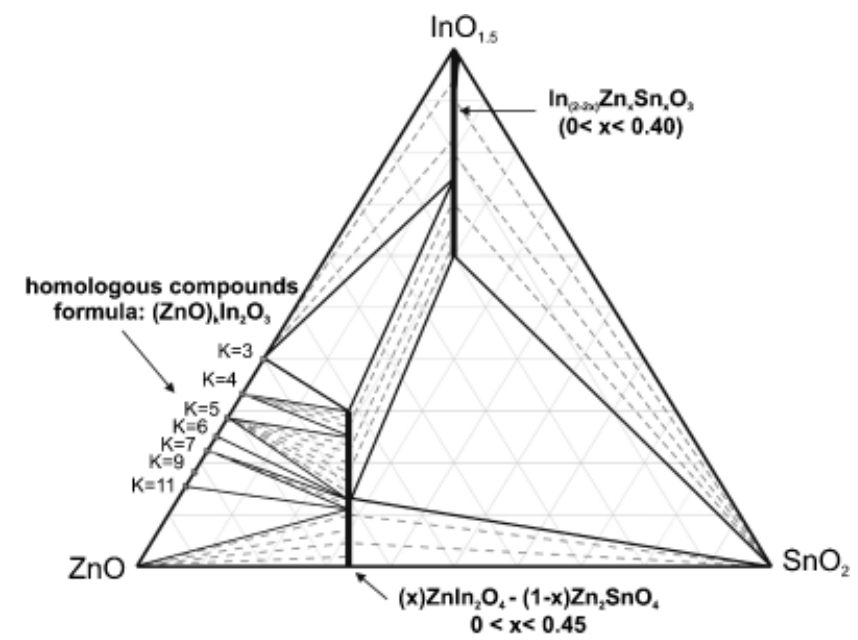

Fig. 4. Subsolidus phase diagram of the $\mathrm{ZnO}-\mathrm{InO}_{1.5}-\mathrm{SnO}_{2}$ system at $1275^{\circ} \mathrm{C}$, without the symbols indicating the experimental compositions and number of phases present. gle boundaries by the appearance and disappearance of those phases. Using this procedure, the $k 6-k 7$-spinel and $k 7-k 11$-spinel compatibility triangles shown in Fig. 3 were established.

There are two differences between the published phase diagram for the $\mathrm{ZnO}-\mathrm{InO}_{1.5}$ binary ${ }^{10}$ and the ternary diagram in the present work. The first is that the $k=9$ homologous compound $\left(\mathrm{Zn}_{9} \mathrm{In}_{2} \mathrm{O}_{11}\right)$ was never observed in ternary phase space. The second difference observed is the presence of the $k=6$ homologous compound $\left(\mathrm{Zn}_{6} \mathrm{In}_{2} \mathrm{O}_{9}\right)$, that Moriga et al. ${ }^{10}$ reported as not being stable below $1325^{\circ} \mathrm{C}$ in the binary. Given the relatively small temperature difference of $50^{\circ} \mathrm{C}$ between the two studies, the lower limit of stability for the $k=6$ phase may have been overestimated by Moriga et al. ${ }^{10}$ It is also possible that the presence of $\mathrm{SnO}_{2}$ stabilizes the $k=6$ phase to lower temperature, and does the opposite for the $k=9$ phase. This would argue for small (but probably not detectable) Sn solubility in at least some of the homologous compounds.

The phase equilibria at the $\mathrm{ZnO}$ end of the ternary system are dominated by tie triangles and two-phase regions between the various homologous series compounds (or $\mathrm{ZnO}$ ) and the spinel phase of varying composition. In fact, if we imagine $\mathrm{ZnO}$ as the $k=\infty$ end member of the $(\mathrm{ZnO})_{k} \cdot \mathrm{In}_{2} \mathrm{O}_{3}$ series, we can trace a progressive increase in the relative activity of $\operatorname{In}_{2} \mathrm{O}_{3}$ as we move away from the $\mathrm{ZnO}-\mathrm{SnO}_{2}$ binary. This activity increase is reflected by a monotonic increase in the indium content of the spinel on one hand, and a corresponding decrease in $k$ value (increase of indium content) in the equilibrium $k$-phase(s) on the other.

Starting from $\mathrm{ZnO}$, there is a two-phase equilibrium between $\mathrm{ZnO}$ and the spinel $\mathrm{Zn}_{(2-x)} \mathrm{Sn}_{(1-x)} \mathrm{In}_{2 x} \mathrm{O}_{4}$ up to $11 \%$ indium $\left(x=0.165\right.$ in $\left.\mathrm{Zn}_{(2-x)} \operatorname{Sn}_{(1-x)} \operatorname{In}_{2 x} \mathrm{O}_{4}\right)$. This is followed by a compatibility triangle between $\mathrm{ZnO}$, the $k=11$ homologous compound $\mathrm{Zn}_{11} \operatorname{In}_{2} \mathrm{O}_{14}$, and the $11 \%$ indium-doped spinel $(x=0.165$ in $\left.\mathrm{Zn}_{(2-x)} \mathrm{Sn}_{(1-x)} \mathrm{In}_{2 x} \mathrm{O}_{4}\right)$.

With increasing indium activity (and increasing indium content in the spinel phase), there follows a series of tie triangles: $k 11-k 7$-spinel, $k 7-k 6$-spinel, $k 6-k 5$-spinel, $k 5-k 4$-spinel, and $k 4$ $k 3$-spinel. These tie triangles are most likely separated by fanshaped two-phase regions emanating from each of the $k$-phases to spinels having a range of compositions. However, only the $k=4,5$, and 7 phases coexist with spinels having a detectable variation in concentration. The $\mathrm{Zn}_{5} \mathrm{In}_{2} \mathrm{O}_{8}$ or $k=5$ compound forms the largest fan-shaped, two-phase region, with $\mathrm{Zn}_{5} \mathrm{In}_{2} \mathrm{O}_{8}$ in equilibrium with spinel from $13 \%$ to $25 \%$ indium $(x \sim 0.2-$ 0.38 in $\left.\mathrm{Zn}_{(2-x)} \operatorname{Sn}_{(1-x)} \operatorname{In}_{2 x} \mathrm{O}_{4}\right)$.

On the tin-rich side of the spinel solid solution, there is a twophase equilibrium between the spinel solid solution having $13 \%-30 \%$ indium $\left(x=0.20-0.45\right.$ in $\left.\mathrm{Zn}_{(2-x)} \operatorname{Sn}_{(1-x)} \mathrm{In}_{2 x} \mathrm{O}_{4}\right)$ and the bixbyite solid solution having $60 \%-80 \%$ indium $(x=0.40$ 0.20 in $\left.\operatorname{In}_{(2-2 x)} \operatorname{Sn}_{x} \mathrm{Zn}_{x} \mathrm{O}_{3}\right)$. We have represented this region as equally spaced (nearly parallel) tie lines, bounded on one side by the $k 3$-bixbyite-spinel tie triangle and on the other by the spinelbixbyite- $\mathrm{SnO}_{2}$ tie triangle. The compositions of spinel and bixbyite in both the tie triangles and the two-phase region were found (by lattice parameter measurements) to be consistent with the tie lines as shown in the phase diagram of Fig. 1.

The most technologically important equilibria in the $\mathrm{ZnO}$ $\mathrm{InO}_{1.5}-\mathrm{SnO}_{2}$ phase diagram involve the most highly conductive TCO phases. For example, the $\mathrm{In}_{2-2 x} \mathrm{Zn}_{x} \mathrm{Sn}_{x} \mathrm{O}_{3}(x=0-0.40)$ bixbyite solid solution is compatible on the one hand with $\mathrm{SnO}_{2}$, and on the other (for $x=0-0.25$ ) with the $k=3$ member of the homologous series of compounds. As a result, these phases should be thermochemically compatible when placed in contact in devices/structures. On the other hand, the spinel phase, which is a relatively poor TCO, is compatible with all three of the highly conductive TCOs - the low- $k$ homologous series compounds, bixbyite, and $\mathrm{SnO}_{2}$.

\section{Conclusions}

The subsolidus phase relationships in the $\mathrm{ZnO}-\mathrm{InO}_{1.5}-\mathrm{SnO}_{2}$ system were investigated at $1275^{\circ} \mathrm{C}$. No new compounds or 
structures were observed within the ternary diagram. Within experimental uncertainty, there was no observable solubility of tin or zinc into any of the homologous series of compounds $(\mathrm{ZnO})_{k} \cdot \mathrm{In}_{2} \mathrm{O}_{3}$ (where $k=3,4,5,7,9,11$ ). The $k=9$ homologous compound was not seen in the ternary phase space. The $k=6$ homologous compound was observed in ternary assemblages, although work on the $\mathrm{ZnO}-\mathrm{InO}_{1.5}$ binary did not observe this compound below $1325^{\circ} \mathrm{C}$. Equilibrium in the $\mathrm{ZnO}$ corner, between the homologous compounds and the spinel phase, was found difficult to achieve. This problem was overcome by utilizing mixtures of the $k=11 \mathrm{Zn}_{11} \mathrm{In}_{2} \mathrm{O}_{14}$ homologous series compound plus spinels with high indium content. This procedure allowed homologous phases with high $k$ values to form and achieve equilibrium with the corresponding spinel compositions. Important compatibilities were identified between the most highly conductive TCO phases in the phase diagram.

\section{References}

${ }^{1}$ D. S. Ginley and C. Bright, "Transparent Conducting Oxides," MRS Bull., 25 [8] 15-8 (2000).

${ }^{2}$ J. H. Bae, J. M. Moon, S. W. Jeong, J. J. Kim, J. W. Kang, D. G. Kim, J. K. Kim, J. W. Park, and H. K. Kim, "Transparent Conducting Indium Zinc Tin Oxide Anode for Highly Efficient Phosphorescent Organic Light Emitting Diodes," J. Electrochem. Soc., 155 [1] J1-6 (2008).

${ }^{3}$ M. S. Grover, P. A. Hersh, H. Q. Chiang, E. S. Kettenring, J. F. Wager, and D. A. Keszler, "Thin-Film Transistors with Transparent Amorphous Zinc Indium Tin Oxide Channel Layer," J. Phys. D-Appl. Phys., 40 [5] 1335-8 (2007).

${ }^{4}$ J. Ni, H. Yan, A. C. Wang, Y. Yang, C. L. Stern, A. W. Metz, S. Jin, L. Wang, T. J. Marks, J. R. Ireland, and C. R. Kannewurf, "MOCVD-Derived Highly Transparent, Conductive Zinc- and Tin-Doped Indium Oxide Thin Films: Precursor Synthesis, Metastable Phase Film Growth and Characterization, and Application as Anodes in Polymer Light-Emitting Diodes," J. Am. Chem. Soc., 127 [15] 5613-24 (2005).

${ }^{5}$ T. Minami, "Transparent Conducting Oxide Semiconductors for Transparent Electrodes," Semicond. Sci. Technol., 20 [4] S35-44 (2005).

${ }^{6}$ H. Agura, H. Okinaka, S. Hoki, T. Aoki, A. Suzuki, T. Matsushita, and M. Okuda, "Low-Resistive and Transparent AZO Films Prepared by PLD in Magnetic Field," Electr. Eng. Jpn., 151 [2] 40-5 (2005).

${ }^{7}$ S. M. Park, T. Ikegami, and K. Ebihara, "Effects of Substrate Temperature on the Properties of Ga-Doped ZnO by Pulsed Laser Deposition," Thin Solid Films, 513 [1-2] 90-4 (2006).

${ }^{8}$ T. Minami, "New n-Type Transparent Conducting Oxides," MRS Bull., 25 [8] 38-44 (2000).

${ }^{9}$ G. B. Palmer, K. R. Poeppelmeier, and T. O. Mason, " $Z n_{(2-x)} \operatorname{Sn}_{(1-x)} \operatorname{In}_{2 x}$ $\mathrm{O}_{4-\text { delta: }}$ : An Indium-Substituted Spinel with Transparent Conducting Properties," J. Solid State Chem., 134 [1] 192-7 (1997).

${ }^{10}$ T. Moriga, D. D. Edwards, T. O. Mason, G. B. Palmer, K. R. Poeppelmeier, J. L. Schindler, C. R. Kannewurf, and I. Nakabayashi, "Phase Relationships and Physical Properties of Homologous Compounds in the Zinc Oxide-Indium Oxide System," J. Am. Ceram. Soc., 81 [5] 1310-6 (1998).

${ }^{11}$ T. Moriga, D. R. Kammler, T. O. Mason, G. B. Palmer, and K. R. Poeppelmeier, "Electrical and Optical Properties of Transparent Conducting Homologous Compounds in the Indium-Gallium-Zinc Oxide System," J. Am. Ceram. Soc., 82 [10] 2705-10 (1999).

${ }^{12}$ N. Naghavi, A. Rougier, C. Marcel, C. Guery, J. B. Leriche, and J. M. Tarascon, "Characterization of Indium Zinc Oxide Thin Films Prepared by Pulsed Laser Deposition Using a $\mathrm{Zn}_{3} \mathrm{In}_{2} \mathrm{O}_{6}$ Target," Thin Solid Films, 360 [1-2] 233-40 (2000).

${ }^{13}$ K. Tominaga, T. Murayama, I. Mori, T. Okamoto, K. Hiruta, T. Moriga, and I. Nakabayashi, "Conductive Transparent Films Deposited by Simultaneous Sputtering of Zinc-Oxide and Indium-Oxide Targets," Vacuum, 59 [2-3] 546-52 (2000).

${ }^{14}$ G. B. Palmer, K. R. Poeppelmeier, and T. O. Mason, "Conductivity and Transparency of $\mathrm{ZnO} / \mathrm{SnO}_{2}$-Cosubstituted $\mathrm{In}_{2} \mathrm{O}_{3}$," Chem. Mater., 9 [12] 3121-6 (1997).

${ }^{15}$ D. R. Kammler, D. D. Edwards, B. J. Ingram, T. O. Mason, G. B. Palmer, A. Ambrosini, and K. R. Poeppelmeier, "Novel Compound and Solid-Solution Transparent Conducting Oxides for Photovoltaics"; pp. 68-77 in Photovoltaics for the 21st Century, Electrochem. Soc. Proc. Vol. 9-11, Edited by V. K. Kapur, R. D. McConnell, D. Carlson, G. P. Ceasar, and A. Rohtagi. The Electrochemical Society, Pennington, NJ, USA, 1999.

${ }^{16}$ M. Marezio, "Refinement of Crystal Structure of $\mathrm{In}_{2} \mathrm{O}_{3}$ at 2 Wavelengths," Acta Crystallogr., 20 [6] 723-8 (1966).

${ }^{17}$ R. W. G. Wyckoff, Crystal Structures, Vol. 1. Interscience Publishers, New York, 1958.

${ }^{18}$ S. C. Abrahams and J1. Bernstei, "Remeasurement of Structure of Hexagonal ZnO," Acta Crystallogr. Section B-Struct. Crystallogr. Cryst. Chem., B 25, 1233 (1969).

${ }^{19}$ G. B. Gonzalez Aviles, "Studies on the Defect Structure of Indium-Tin Oxide Using X-Ray and Neutron Diffraction"; Ph.D. Materials Science, Northwestern University, Evanston, IL. 230 pp. 2003
${ }^{20} \mathrm{~W}$. J. Heward and D. J. Swenson, "Phase Equilibria in the Pseudo-Binary $\mathrm{In}_{2} \mathrm{O}_{3}-\mathrm{SnO}_{2}$ System," J. Mater. Sci., 42 [17] 7135-40 (2007).

${ }^{21}$ G. B. Gonzalez, T. O. Mason, J. P. Quintana, O. Warschkow, D. E. Ellis, J. H Hwang, J. P. Hodges, and J. D. Jorgensen, "Defect Structure Studies of Bulk and Nano-Indium-Tin Oxide," J. Appl. Phys., 96 [7] 3912-20 (2004).

${ }^{22}$ J. L. Bates, C. W. Griffin, D. D. Marchant, and J. E. Garnier, "Electrical Conductivity, Seebeck Coefficient, and Structure of $\mathrm{In}_{2} \mathrm{O}_{3}-\mathrm{SnO}_{2}$, , Bull. Am. Ceram. Soc., 65 [4] 673-8 (1986).

${ }^{23}$ D. D. Edwards and T. O. Mason, "Subsolidus Phase Relations in the $\mathrm{Ga}_{2} \mathrm{O}_{3}$ $\mathrm{In}_{2} \mathrm{O}_{3}-\mathrm{SnO}_{2}$ System," J. Am. Ceram. Soc., 81 [12] 3285-3292 (1998).

${ }^{24} \mathrm{H}$. Enoki, J. Echigoya, and H. Sato, "The Intermediate Compound in the $\mathrm{In}_{2} \mathrm{O}_{3}-\mathrm{SnO}_{2}$ System," J. Mater. Sci., 26 [15] 4110-5 (1991).

${ }^{25}$ Phase Diagrams for Ceramists. American Ceramic Society, Westerville, $\mathrm{OH}$.

${ }^{26} \mathrm{D}$. Kovacheva and K. Petrov, "Preparation of Crystalline $\mathrm{ZnSnO}_{3}$ from $\mathrm{Li}_{2} \mathrm{SnO}_{3}$ by Low-Temperature Ion Exchange," Solid State Ionics, 109 [3-4] 32732 (1998).

${ }^{27}$ G. B. Palmer and K. R. Poeppelmeier, "Phase Relations, Transparency and Conductivity in $\mathrm{Ga}_{2} \mathrm{O}_{3}-\mathrm{SnO}_{2}-\mathrm{ZnO}$," Solid State Sci., 4 [3] 317-22 (2002).

${ }^{28}$ M. Peiteado, Y. Iglesias, J. De Frutos, J. F. Fernandez, and A. C. Caballero, "Preparation of $\mathrm{ZnO}-\mathrm{SnO}_{2}$ Ceramic Materials by a Coprecipitation Method," Bol. Soc. Esp. Ceram. V., 45 [3] 158-62 (2006).

${ }^{29}$ R. D. Shannon and C. T. Prewitt, "Effective Ionic Radii in Oxides and Fluorides," Acta Crystallogr. Section B-Struct. Crystallogr. Cryst. Chem., B25, 925 47 (1969).

${ }^{30}$ S. P. Harvey, T. O. Mason, D. B. Buchholz, R. P. H. Chang, C. Körber, and A. Klein, "Carrier Generation and Inherent Off-Stoichiometry in $\mathrm{Zn}, \mathrm{Sn} \mathrm{Co}-$ Doped Indium Oxide (ZITO) Bulk and Thin Film Specimens," J. Am. Ceram. Soc., 91 [2] 467-72 (2008).

${ }^{31}$ D. L. Young, D. L. Williamson, and T. J. Coutts, "Structural Characterization of Zinc Stannate Thin Films," J. Appl. Phys., 91 [3] 1464-71 (2002).

\section{Appendix A}

Table A1. Composition of All Specimens Involved in This Study, Along with the Phases Present

\begin{tabular}{|c|c|c|c|}
\hline \multicolumn{3}{|c|}{ Specimen composition } & \multirow[b]{2}{*}{ Phases present } \\
\hline Cation \%In & Cation $\% \mathrm{Zn}$ & Cation $\% \mathrm{Sn}$ & \\
\hline 0.00 & 66.66 & 33.34 & Spinel $(x=0)$ \\
\hline 4.00 & 56.00 & 40.00 & Spinel $+\mathrm{SnO}_{2}$ \\
\hline 5.00 & 70.00 & 25.00 & $\mathrm{ZnO}+$ spinel \\
\hline 6.00 & 80.00 & 14.00 & $\mathrm{ZnO}+$ spinel $+k 11$ \\
\hline 7.00 & 54.50 & 38.50 & Spinel $+\mathrm{SnO}_{2}$ \\
\hline 7.33 & 68.33 & 24.34 & $\mathrm{ZnO}+$ spinel \\
\hline 7.50 & 82.50 & 10.00 & $\mathrm{ZnO}+$ spinel $+k 11$ \\
\hline 10.00 & 67.50 & 22.50 & $\mathrm{ZnO}+$ spinel $+k 11$ \\
\hline 15.00 & 58.17 & 26.83 & Spinel $(x=0.225)$ \\
\hline 15.38 & 84.62 & 0.00 & $\mathrm{In}_{2} \mathrm{Zn}_{11} \mathrm{O}_{14}(k=11)$ \\
\hline 16.67 & 58.33 & 25.00 & Spinel $(x=0.25)$ \\
\hline 16.69 & 76.74 & 6.58 & $k 7+k 11+$ spinel \\
\hline 16.92 & 75.30 & 7.78 & $k 7+k 11+$ spinel \\
\hline 17.40 & 79.50 & 3.09 & $k 7+k 11+$ spinel \\
\hline 17.77 & 70.19 & 12.04 & $k 7+$ spinel \\
\hline 18.11 & 68.11 & 13.78 & $k 6+k 7+$ spinel \\
\hline 18.18 & 74.89 & 6.92 & $k 7+k 11+$ spinel \\
\hline 18.18 & 81.82 & 0.00 & $\mathrm{In}_{2} \mathrm{Zn}_{9} \mathrm{O}_{12}(k=9)$ \\
\hline 18.31 & 66.92 & 14.77 & $k 5+k 6+$ spinel \\
\hline 18.78 & 72.83 & 8.40 & $k 7+$ spinel \\
\hline 18.91 & 72.36 & 8.73 & $k 7+$ spinel \\
\hline 19.04 & 62.49 & 18.47 & $k 5+$ spinel \\
\hline 19.36 & 70.79 & 9.85 & $k 7+k 6+$ spinel \\
\hline 19.47 & 71.02 & 9.51 & $k 7+k 6+$ spinel \\
\hline 19.50 & 74.30 & 6.20 & $k 7+k 11+$ spinel \\
\hline 19.59 & 73.98 & 6.44 & $k 7+$ spinel \\
\hline 19.83 & 73.35 & 6.82 & $k 7+$ spinel \\
\hline 20.06 & 72.78 & 7.16 & $6+7+s p$ \\
\hline 20.21 & 72.40 & 7.40 & $6+7+\mathrm{sp}$ \\
\hline 20.33 & 67.42 & 12.25 & $k 5+k 6+$ spinel \\
\hline 20.63 & 66.38 & 12.99 & $k 5+k 6+$ spinel \\
\hline 20.88 & 65.52 & 13.60 & $K 5+$ spinel \\
\hline 20.97 & 70.48 & 8.56 & $k 6+k 7+$ spinel \\
\hline 21.25 & 64.22 & 14.53 & $k 5+$ spinel \\
\hline
\end{tabular}


Table A1. Continued

\begin{tabular}{|c|c|c|c|}
\hline \multicolumn{3}{|c|}{ Specimen composition } & \multirow[b]{2}{*}{ Phases present } \\
\hline Cation \%In & Cation $\% \mathrm{Zn}$ & Cation $\% \mathrm{Sn}$ & \\
\hline 21.73 & 62.56 & 15.71 & $k 5+$ spinel \\
\hline 22.22 & 77.78 & 0.00 & $\mathrm{In}_{2} \mathrm{Zn}_{7} \mathrm{O}_{10}(k=7)$ \\
\hline 22.53 & 66.52 & 10.95 & $k 5+$ spinel \\
\hline 24.00 & 54.70 & 21.30 & Spinel $(x=0.36)$ \\
\hline 24.05 & 62.67 & 13.28 & $k 5+$ spinel \\
\hline 25.26 & 59.61 & 15.13 & $k 5+$ spinel \\
\hline 26.44 & 56.63 & 16.94 & $k 4+k 5+$ spinel \\
\hline 26.90 & 55.45 & 17.65 & $k 4+$ spinel \\
\hline 28.00 & 52.70 & 19.30 & Spinel $(x=0.42)$ \\
\hline 28.57 & 71.43 & 0.00 & $\mathrm{In}_{2} \mathrm{Zn}_{5} \mathrm{O}_{8} k=5$ \\
\hline 29.00 & 26.00 & 45.00 & Bixbyite + spinel $+\mathrm{SnO}_{2}$ \\
\hline 29.12 & 53.64 & 17.23 & $k 4+$ spinel \\
\hline 30.00 & 51.70 & 18.30 & Spinel $(x=0.40)$ \\
\hline 32.00 & 56.00 & 12.00 & $k 3+k 4+$ spinel \\
\hline 33.30 & 66.70 & 0.00 & $\mathrm{In}_{2} \mathrm{Zn}_{4} \mathrm{O}_{7}(k=4)$ \\
\hline 33.33 & 50.00 & 16.67 & $k 3+$ spinel + bixbyite \\
\hline 38.00 & 61.00 & 1.00 & $k 3+k 4+$ spinel \\
\hline 39.00 & 61.00 & 0.00 & $k 3+k 4$ \\
\hline 39.60 & 60.20 & 0.20 & $k 3+k 4+$ spinel \\
\hline 40.00 & 60.00 & 0.00 & $\mathrm{In}_{2} \mathrm{Zn}_{3} \mathrm{O}_{6}(k=3)$ \\
\hline 40.00 & 59.40 & 0.60 & $k 3+$ spinel + bixbyite \\
\hline 40.00 & 57.00 & 3.00 & $k 3+$ spinel + bixbyite \\
\hline 41.00 & 59.00 & 0.00 & $k 3+\mathrm{In}_{2} \mathrm{O}_{3}$ \\
\hline 42.00 & 37.00 & 21.00 & Bixbyite + spinel \\
\hline 49.20 & 41.80 & 9.00 & $k 3+$ bixbyite + spinel \\
\hline 55.00 & 22.50 & 22.50 & Bixbyite + spinel $+\mathrm{SnO}_{2}$ \\
\hline 60.00 & 27.50 & 12.50 & $k 3+$ bixbyite + spinel \\
\hline 60.00 & 17.50 & 22.50 & Bixbyite $+\mathrm{SnO}_{2}$ \\
\hline 60.00 & 22.50 & 17.50 & Bixbyite + spinel \\
\hline 60.00 & 20.00 & 20.00 & Bixbyite $(x=0.40)$ \\
\hline 70.00 & 17.50 & 12.50 & Bixbyite $+k 3+$ spinel \\
\hline 70.00 & 12.50 & 17.50 & Bixbyite $+\mathrm{SnO}_{2}$ \\
\hline 70.00 & 15.00 & 15.00 & Bixbyite $(x=0.30)$ \\
\hline 76.00 & 14.00 & 10.00 & Bixbyite $+k 3$ \\
\hline 80.00 & 7.50 & 12.50 & Bixbyite $+\mathrm{SnO}_{2}$ \\
\hline 80.00 & 12.50 & 7.50 & Bixbyite $+k 3$ \\
\hline 80.00 & 15.00 & 5.00 & Bixbyite $+k 3$ \\
\hline 80.00 & 10.00 & 10.00 & Bixbyite $(x=0.20)$ \\
\hline 90.00 & 2.50 & 7.50 & Bixbyite $+\mathrm{SnO}_{2}$ \\
\hline 90.00 & 7.50 & 2.50 & Bixbyite $+k 3$ \\
\hline 90.00 & 5.00 & 5.00 & Bixbyite $(x=0.10)$ \\
\hline 94.00 & 0.50 & 5.50 & Bixbyite $+\mathrm{SnO}_{2}$ \\
\hline 94.00 & 5.50 & 0.50 & Bixbyite $+k 3$ \\
\hline 94.00 & 3.00 & 3.00 & Bixbyite $(x=0.06)$ \\
\hline 95.00 & 2.50 & 2.50 & Bixbyite $(x=0.05)$ \\
\hline 98.00 & 0.00 & 2.00 & ITO \\
\hline
\end{tabular}

The specimens are arranged by increasing indium content. The ' $k$ ' value corresponds to the phase in the $(\mathrm{ZnO})_{k} \cdot \mathrm{In}_{2} \mathrm{O}_{3}$ series of compounds. For the singlephase solid solution specimens, the $x$ value given corresponds the composition of the solid solution, $\mathrm{In}_{2-2 x} \mathrm{Zn}_{x} \mathrm{Sn}_{x} \mathrm{O}_{3}(x=0-0.40)$ and $\mathrm{Zn}_{(2-x)} \mathrm{Sn}_{(1-x)} \operatorname{In}_{2 x} \mathrm{O}_{4}$ for the bixbyite and spinel solid solutions, respectively. 